\title{
Assessment of knowledge, attitude and practices of personal and oral hygiene among undergraduate university students in Sulaimani city
}

\author{
Akam Mustafa Hasan \\ Community health department. \\ Technical College of Health, \\ Sulaimani Polytechnic University, \\ Sulaimani, Iraq \\ Akam.hasan@spu.edu.iq
}

\author{
Mardin Othman Abdulqadir* \\ Community health department. \\ Technical College of Health \\ Sulaimani Polytechnic University \\ Sulaimani, Iraq \\ mardinothman@yahoo.com
}

\begin{abstract}
Poor hygiene performance and insufficient sanitary conditions assume real parts in the expanded weight of communicable diseases inside developing nations. Lack of resources such as hand washing materials, water and sanitation facilities may be essential factors why students do not wash their hands, also struggling of affordable toothpaste and absence of awareness regarding oral hygiene may be affected by improper cleaning teeth and tongue. This study was carried out to assess the knowledge, attitude and practices $(K A P)$ of personal and oral hygiene among undergraduate university students in Sulaimani city /Iraq and evaluated the degree to which appropriate information of hygiene was related with individual hygiene character. This cross-sectional study was carried out among 1055 undergraduate students who were met via trained staff. Data comprised of cleanliness and hand washing practices, learning about sanitation, individual cleanliness qualities, nearness of gastrointestinal parasitic disease, oral and dental diseases including dental decay and bad breathes. University students with satisfactory information of legitimate personal and oral hygiene probably had clean clothes $68.8 \%$ ( $P$ value $<0.05)$, clean hair $72 \%(0.0001 P$ value $)$, fingernail trimmed $139 \%$ ( $P$ value $>0.05)$, clean teeth $59.4 \%$ ( $P$ value $<0.05)$, good mouth breath $57 \%$ (P value <0.05). Approximately $57.2 \%$ of students were delegated having sufficient information of legitimate cleanliness (P value $<0.05)$. Most students preferred hand washing after defecation (96.5\%) (P value $<0.05$ ), while $93.8 \%$ revealed utilizing shampoo. On the other hand $62.7 \%$ of contributors reported brushing their teeth before going to sleep ( $P$ value $<0.05)$ and $74 \%$ of participants revealed cleaning their tongue sometimes $(P$ value $<$ 0.01). this study discovered underscore the requirement for more cleanliness training in universities; and give target confirm that may direct the improvement of far reaching personal, oral hygiene and health mediation programs in Sulaimani universities. Furthermore the effective usage of this study is probably going to significantly weaken the transmissible diseases.
\end{abstract}

Keywords: knowledge, attitude, practices, personal hygiene, oral hygiene, university students.

\section{INTRODUCTION}

A broad division of the world's illness and destruction is inferable from transferable disorders [1]. 62\% and 31\% Africa and Southeast Asia died because of transferrable diseases [2]. This pattern is particularly outstanding in developing countries where intense respiratory and intestinal infections are the vital causes of morbidity and mortality among youthful kids [1]. Insufficient sanitary conditions and poor hygiene practices assume significant role in increasing transferable infections inside these developing nations.

Earlier hygiene articles have shown that adolescents with appropriate hand washing practices are less likely to report gastrointestinal and respiratory manifestations $[4,5]$. Hand washing with cleanser has been accounted for diminishing diarrheal diseases by $44 \%$ and respiratory infections by $23 \%[2,6]$. Whereas, globally, the rates of hands are washed with cleanser ranged from $0-34 \%$ of the time [7]. A review carried out by the Public-Private Partnership for Hand Washing Worldwide (PPPHW) which incorporated a few subSaharan African nations (i.e. Kenya, Senegal, Tanzania, and Uganda) showed that $17 \%$ of members washed their hands with soap after defecation using the latrines, while $45 \%$ of them water to wash their hands [2].

Absence of hygiene resources particularly cleanser and water, also inappropriate sanitation facilities might be two of the fundamental reasons why teenagers don't wash their hands $(8,9)$. Generally in developing countries such as Ethiopia, only $8 \%$ of people have can approach adequate sanitation facilities [10]. In rural area of Amhara in Ethiopia, just $21 \%$ of restrooms had hand washing resources, furthermore, less than $4 \%$ of houses had available sanitation facilities [9].

Moreover, having suitable resources and facilities, personal hygiene practices are intensely impacted by students' knowledge and behavior towards cleanliness. In a review carried out in Senegal, stated the reasons for not washing hands included stubbornness (not having any desire to take advices of adults), laziness, the hurry to go to breaks and playing time, and the smells come from the toilets [10]. Regardless of these negative behaviour towards hand washing, many youthds improved hand washing practices and behavior [11]. According to the PPPHW study that carried out in subSaharan Africa, proper hand washing motivation factors 
involved avoidance of disgust (i.e. avoidance from dirt and smell of defecation), encourage (i.e. teaching youngsters to wash hands so they remain healthy), status (i.e. clean individuals are more recognized), association (i.e. cleanliness is related with better economic status), captivation (i.e. cleaner individuals are more likeable), solace (i.e. feeling and smelling fresh from hands), and fear (i.e. avoidance the chance of getting diseases) [12]. Moreover, students did not have any desire to miss school caused by diseases because they would be able spend more time with their friends in the schools and universities [11]. In addition, if the youngsters had clean hands, they would have clean books and get good grades [11].

A study was led by the United Nations Children's Fund (UNICEF) and the Ethiopian Ministry of Health found that contributors in African countries had poor knowledge, attitude and practices towards personal hygiene [13]. Also the same study indicated that $60 \%$ of children did not know that human waste causes the transmission of illnesses [13]. Main personal hygiene criteria such as washing hands with cleanser was poorly shown particularly in rural regions [13]. Another review was conducted by the Research-roused Policy and Practice Learning in Ethiopia (RiPPLE), the program designated to survey the household in Asian and African rural areas, discovered that hand washing practices were reported likely poor [14]. In addition to knowledge and awareness regarding appropriate hygiene new hand washing services, have prompted several changes in attitude and information, yet the frequency of hand washing stays low in this region [14].

Earlier studies about individual hygiene determine that awareness impacts one's hand washing faith and practices. Past reviews carried out in the Middle East deliver restricted facts about KAP of hygiene. Moreover, several researches have analyzed cleanliness knowledge, attitude and practices particularly among school children. Aim of the study: This study was aimed to contribute the information about the level of knowledge, assess the attitude and the practices of undergraduate students in sulaimani universities towards personal and oral hygiene.

\section{METHODS AND MATERIALS}

\section{Setting}

This study design was cross-section was in Sulaimani city/Iraq was started from $15^{\text {th }}$ November 2015 to $15^{\text {th }}$ June 2016. All the samples were taken from Sulaimani Universities, the first place was Sulaimani Polytechnic University, which includes Health, Administration, Engineering and Informatics Technical colleges, Sulaimani Technical institute and Computer Science institute, the second place was University of Sulaimani, the third place was Jihan University and final place was Komar University of Science and Technology.

\section{Study population}

The study population was Sulaimani undergraduate students in level 1 to 4 . The last example size was 1055 university students (512 females and 543 males)

\section{Ethical consideration}

It was essential to gain ethical consideration when conducting this study involves primary data collection and there was direct (questionnaire and interview) dealing with human. Ethical consideration paper work was submitted from the department to the colleges and institution to collect data, in addition to keep students' data confidentiality. The approval from the head of the universities was additionally allowed preceding the initiation of this study.

\section{Procedure and research instruments}

Consider staff comprised of one supervisor, five undergraduate students and one research assistant. Every student was talked with utilizing an organized survey in a room particularly committed for this study in each university. The survey was at first drafted in English, translated to Kurdish language, and afterward pre-tested in Sulaimani Polytechnic University/ Health Technical College to evaluate the reasonableness to duration, dialect propriety, content legitimacy, and question clarity

\section{Variable specification}

The questionnaire comprised of sexual orientation, frequencies of showering, washing hair, brushing teeth, and washing clothes (each 1-7 days, 7-14 days, >14 day), cleaning teeth by dentist (Necessity times, three months, six months and never cleaned their tooth). Undergraduate students were questioned about the kind of materials utilized for showering and washing hair (shampoo, soap and water), brushing teeth materials (toothpaste, dental floss, mouth wash and tooth pick), ways for choosing types of toothpaste (dentist's prescription, they choose it by themselves and according to price), knowledge to scientific using of dental floss (yes, no and don't know). Different inquiries regarding hand washing and oral hygiene included: if hands were washed (yes, no) (after defecation, before and after meals); materials utilized for hand washing (hand shampoo, soap and water), time for brushing their teeth (before bed, after breakfast, after meals and sometimes), bushing their tongue (yes, no and sometimes) and brushing tongue materials (toothbrush and tongue brush).

Each interview objectively watched personal and oral hygiene during the interview, personal hygiene was also evaluated by interviewers to assess the cleanliness of university students. A List was used included for the following queries: clean dresses (yes, no), clean faces (yes, no), fingernail trimmed (yes, no), clean teeth (yes, no) and bad mouth breath (yes, no). The general presence including condition of clothes, fingernails, face, hair and general appearance of teeth were also watched by the interviewers. 


\section{Data analysis}

The collected data was scored by giving the code number according to the answer in the questionnaire, and then these codes were transferred to Microsoft Excel database and the results were analysed by using SPSS statistical software (version 17.0) to present the tables, charts and graphs and $\mathrm{P}$ value $(\mathrm{P}<0.05)$ was considered statistically significant. Frequency distribution, number and percentage were calculated to measure the hygiene and oral practice. The descriptive statistics and statistical significance of any difference between the two genders were determined using the Chi-square test.

\section{RESULTS}

Table 1, According to sexual orientation and personal hygiene of 1055 undergraduate students demonstrate $49 \%(\mathrm{~N}=512)$ of them were female and $51 \%(\mathrm{~N}=543)$ of them were male with mean age 22.1 years old. Around, $97 \%(\mathrm{~N}=1024)$ of the understudies revealed showering for less than 7 days (i.e. good cleanliness practices) (0.0001 $\mathrm{P}$ value). Additionally, around 97\% ( $\mathrm{N}=1024)$ and $73.5 \%$ (775) of the students reported washing their hair and brushing their teeth several times in a week (0.05 and $0.00001 \mathrm{P}$ values). About $71.8 \%(\mathrm{~N}=757)$ of undergraduates showed had dental cleaning when plaque is build-up on their teeth $(0.00001 \mathrm{P}$ value $)$. Also $73.5 \%(\mathrm{~N}=775)$ washing their clothes for no less than 7 days (0.00001 $\mathrm{P}$ value).

Table 2, showed $84.4 \%$ ( $\mathrm{N}=888$ ) of students used soap and water to wash their hands $(0.00001 \mathrm{P}$ value $)$. Furthermore, $93.4 \%(\mathrm{~N}=985)$ of undergraduate students revealed using shampoo to wash their hair $(0.07 \mathrm{P}$ value). Moreover, \%77.5 ( $\mathrm{N}=877)$ of students reported utilizing toothpaste to wash their teeth $(0.001 \mathrm{P}$ value $)$. $38 \%$ (Mean= 400) of understudies showed choosing the type of toothpaste according to the price of the item, And around $40 \%(\mathrm{~N}=442)$ of participants reported they do not know scientifically using dental floss $(0.00001 \mathrm{P}$ value).

Table 3, demonstrated that $72.8 \% \quad(\mathrm{~N}=738)$ of participants reported washing their hands before and after meals (0.00001 $\mathrm{P}$ value), 94.5\% (N=997) of students revealed washing hands after defecation (0.00001 $\mathrm{P}$ value) and $74.3 \%(\mathrm{~N}=784)$ of understudies generally used shampoo to wash their hands. On the other hand, $62.9 \% \quad(\mathrm{~N}=580)$ of students reported brushing their teeth before going to sleep $(0.00001 \mathrm{P}$ value), $74.1 \%(\mathrm{~N}=686)$ of participants washed their tongue irregularly and $98.1 \% \quad(\mathrm{~N}=1034)$ of undergraduates used their toothbrush to wash their tongue (0.00001 $\mathrm{P}$ value). The results of observing personal and oral hygiene by the interviews were statistically significant $(\mathrm{P}<0.05)$. More than $57.2 \%$ of the students were named having sufficient information of legitimate cleanliness

Table 4 , showed that $42.8 \%$ of the undergraduates did not have proper knowledge of personal hygiene. majority of the students $68.8 \%(\mathrm{~N}=693)$ dressed clean clothes $(0.00001 \mathrm{P}$ value $), 72 \%(\mathrm{~N}=759)$ of the students hair observed as clean (0.9 $\mathrm{P}$ value), $86.1 \%(\mathrm{~N}=854)$ of the participants' fingernails were not trimmed $(0.00001$ $\mathrm{P}$ value $), 58.2 \%(\mathrm{~N}=662)$ of the undergraduates face appeared clean ( $0.05 \mathrm{P}$ value $), 59.4 \% \quad(\mathrm{~N}=570)$ of the students teeth were seen clean $(0.00001 \mathrm{P}$ value $), 57 \%$ $(\mathrm{N}=570)$ of the students mouth reported did not have bad breath (0.05).

\section{DISCUSSION}

In this study of university students from level 1 to 4 , we assessed the knowledge, attitudes and practices for both personal and oral hygiene of the students surveyed, $57.2 \%$ were classified as having proper knowledge of hygiene. This information is important for the act of proper hygiene practice of students in the universities. We additionally assessed the personal hygiene characteristics. Overall our discoveries are predictable with previous reviews that have recorded learning and practices of cleanliness among school youngsters in developing nations [17].

This study indicates $62.9 \%$ of university students brushed their teeth before going to sleep, in contrast studies carried out in Nigeria and developing countries revealed $71.9 \%$ and $62.7 \%$ of undergraduates brushed their teeth twice a day $[21,22]$. Almost $27.8 \%$ of students reported brushing teeth after breakfast, this finding is anticipated with past researches that have shown $28 \%$ of adults used to brush their teeth at breakfast time so they could feel fresh at the beginning of the day [23]. In, addition, majority of students $(98.1 \%)$ used toothbrush to brush their tongue, which is similar to past studies reporting $(81.8 \%)$ of the students brushed their tongues by using tooth brush in the developing countries [22].

Overall, majority of the undergraduates announced washing hands before meals. The rates of those students were about $70 \%$. Remarkably, the self-reported incidence of hand washing before meals among undergraduates in our research is generously higher than frequencies announced from surveys of youths in comparison to the other countries. For example, students from Bangladesh showed that $75.9 \%$ and $46.9 \%$ of students revealed washing hands before suppers [17].

Washing hands after defecation is one of the most effective ways to prevent gastrointestinal parasitic infections [2, 6]. This behaviour may be negatively influenced by factors such as laziness, the rush to play with friends, or even the lack of hand washing facilities in the university toilets [11]. In contrast, studies conducted in Colombia and India reported that $82.5 \%$ and $86.4 \%$ of students showed washing their hands after defecation $[16,20]$.

In a previous study showed that brushing tooth before going to sleep could be the most effective method to reduce dental caries [24]. Whereas in this study most of 
the undergraduate students believed that brushing their teeth before going to bed is very important to eliminate dental caries, gingival diseases and also oral halitosis, but this attitude can be negatively affected by some other factors for example laziness and lack of awareness.

In this study majority of the understudies washed their hands with hand shampoo after visiting the toilet (90\%). This shows having good resources and facilities of hand washing in the universities. However past studies in the developing countries demonstrated $7 \%$ of the students reported having water and soap to wash their hands in the school in the developing countries [24]. While those that had hand washing materials were more likely to wash their hands after defecation.

Also tongue cleaning is one of the important factor to maintain good oral hygiene, a few microscopic organisms can colonize on the tongue, they are diminished by tongue cleaning $[25,26]$. In this study, majority of the students (74\%) reported brushing tongue not regularly, it means that students do not have proper knowledge and attitudes towards oral hygiene.

A few restrictions must be considered when translating our outcomes. Firstly, understudies' self-reported practices may have brought about over-reporting of appropriate cleanliness practices. This bias was mitigated by involving students' personal hygiene characters objective measures. Secondly, our review was restricted to understudies from level 1 to 4 and the individuals who were available in school. Adolescents absent because of disease or having sessions were excluded, in this way results may not be summed up to all students. Thirdly, the cross-sectional review configuration makes deciding causality impossible. Finally, there was no relationship between reported personal hygiene and adequate knowledge of hygiene, which might be qualified to small sample size and probable over revealing of hygiene practices.

Significantly, Ministry of Education of Iraq and UNICEF have been making progresses towards improving access to hygiene materials and to expand the ability concerning sanitation and personal and dental hygiene [18]. In 2013, UNICEF delivered the Water, Sanitation, and Hygiene (WASH) Program to promote hand washing and sanitation practice in low income countries including Iraqi Kurdistan Region [19]. These activities, combined to all school-based wellbeing and hygiene educational program that encouraged individual cleanliness at home and at school should add up to better wellbeing and personal hygiene practice and knowledge conditions among students.

This review targets two key issues that must be tended to while making wellbeing and hygiene advancement programs. Firstly, just $57.2 \%$ of understudies were delegated having legitimate personal and oral hygiene information. To increase this rate, public health organizations can be formed to explain students about infection causation and transmission, show appropriate hand washing, cleanliness practices, techniques and materials for cleaning teeth, and give motivations to great hygiene procedures. Secondly, hygiene practices depend on accessibility of adequate hygiene resources.

Table 1. Sexual orientation, personal and oral hygiene among university students

\begin{tabular}{|c|c|c|c|c|c|c|}
\hline Characteristics & $\begin{array}{c}\text { Stage 1 } \\
\mathrm{N}=190(\%)\end{array}$ & $\begin{array}{c}\text { Stage } 2 \\
\mathrm{~N}=209(\%)\end{array}$ & $\begin{array}{c}\text { Stage 3 } \\
\mathrm{N}=252(\%)\end{array}$ & $\begin{array}{c}\text { Stage } 4 \\
N=404(\%)\end{array}$ & $\mathbf{X} 2$ & $\begin{array}{c}\mathbf{P} \\
\text { value }\end{array}$ \\
\hline \multicolumn{7}{|l|}{ Gender } \\
\hline Male & $90(47.4)$ & $111(53.1)$ & $125(49.6)$ & $217(53.7)$ & \multirow{2}{*}{2.7} & \multirow{2}{*}{0.5} \\
\hline Female & $100(52.6)$ & $98 \quad(46.9)$ & $127(50.4)$ & $187(46.3)$ & & \\
\hline \multicolumn{7}{|l|}{ Hygiene practices } \\
\hline \multicolumn{7}{|l|}{ Taking shower } \\
\hline $1-7$ days & $185(97.3)$ & $199(95.3)$ & $237(94.1)$ & $403(99.7)$ & \multirow{2}{*}{20.9} & \multirow{2}{*}{0.00001} \\
\hline 8-14 days & $5(2.7)$ & $10(4.7)$ & $15(5.9)$ & $1(0.3)$ & & \\
\hline \multicolumn{7}{|l|}{ Washing hair } \\
\hline 1-7 days & $184(96.8)$ & $199(95.2)$ & $241(95.6)$ & $399(98.8)$ & \multirow{2}{*}{8.5} & \multirow{2}{*}{0.05} \\
\hline 8-14 days & $6(3.2)$ & $10(4.8)$ & $11(4.4)$ & $5(1.2)$ & & \\
\hline \multicolumn{7}{|l|}{ Brushing teeth } \\
\hline 1-7 days & $105(55.3)$ & $150(71.8)$ & $170(67.5)$ & $350(86.6)$ & \multirow{2}{*}{73.2} & \multirow{2}{*}{0.00001} \\
\hline 8-14 days & $85(44.7)$ & $59(28.2)$ & $82(32.5)$ & $54(13.4)$ & & \\
\hline \multicolumn{7}{|c|}{ Cleaning teeth by the dentist (scaling and polishing) } \\
\hline Presence of plaque & $154(81.1)$ & $155(74.2)$ & $114(57.4)$ & $334(82.7)$ & \multirow{4}{*}{297.6} & \multirow{5}{*}{0.00001} \\
\hline 3 months & $7(3.7)$ & $9(4.3)$ & $7(2.7)$ & $9(2.2)$ & & \\
\hline 6 months & $9(4.7)$ & $0(0)$ & $96(38.1)$ & $1(0.2)$ & & \\
\hline Never & $20(10.5)$ & $45(21.5)$ & $60(23.8)$ & $60(14.9)$ & & \\
\hline \multicolumn{6}{|l|}{ Washing clothes } & \\
\hline 1-7 days & $105(55.3)$ & $150(71.8)$ & $170(67.5)$ & $350(86.6)$ & \multirow{2}{*}{73.2} & \multirow{2}{*}{0.00001} \\
\hline 8-14 days & $85(44.7)$ & $59(28.2)$ & $82(32.5)$ & $54(13.4)$ & & \\
\hline st & & & & & & \\
\hline
\end{tabular}


Table 2. Knowledge, attitude and personal hygiene toward sanitation of university students

\begin{tabular}{|c|c|c|c|c|c|c|}
\hline Characteristics & $\begin{array}{c}\text { Stage 1 } \\
\mathrm{N}=190(\%)\end{array}$ & $\begin{array}{c}\text { Stage } 2 \\
\mathrm{~N}=209(\%)\end{array}$ & $\begin{array}{c}\text { Stage 3 } \\
\mathbf{N}=252(\%)\end{array}$ & $\begin{array}{c}\text { Stage } 4 \\
\mathrm{~N}=404(\%)\end{array}$ & $\mathbf{X} 2$ & $P$ value \\
\hline \multicolumn{7}{|c|}{ Materials used for bathing } \\
\hline Soap & $110(57.9)$ & $188(90)$ & $221(87.7)$ & $369(91.3)$ & \multirow{3}{*}{136.9} & \multirow{3}{*}{0.0001} \\
\hline Shampoo & $80(42.1)$ & $20(9.6)$ & $31(12.3)$ & $30(7.4)$ & & \\
\hline Water only & $0(0)$ & $1(0.4)$ & $0(0)$ & $5(1.2)$ & & \\
\hline \multicolumn{7}{|c|}{ Materials used for hair washing } \\
\hline Shampoo & $185(97.4)$ & $199(95.2)$ & $229(90.9)$ & $372(92.1)$ & \multirow{3}{*}{11.5} & \multirow{3}{*}{0.07} \\
\hline Soap & $5(2.6)$ & $9(4.3)$ & $20(7.9)$ & $25(6.2)$ & & \\
\hline Water only & $0(0)$ & $1(0.5)$ & $3(1.2)$ & $7(1.7)$ & & \\
\hline \multicolumn{7}{|c|}{ Materials used for teeth brushing } \\
\hline Toothpaste & $148(77.9)$ & $167(79.9)$ & $199(79)$ & $363(89.6)$ & \multirow{4}{*}{27.9} & \multirow{4}{*}{0.001} \\
\hline Dental floss & $16(8.4)$ & $10(4.8)$ & $11(4.4)$ & $11(2.7)$ & & \\
\hline Mouth wash & $23(12.1)$ & $30(14.3)$ & $38(15)$ & $29(7.2)$ & & \\
\hline Tooth pick & $3(1.6)$ & $2(1)$ & $4(1.6)$ & $1(0.2)$ & & \\
\hline \multicolumn{7}{|c|}{ Choosing toothpaste } \\
\hline Dentist & $9(4.7)$ & $101(48.3)$ & $50(19.8)$ & $62(15.3)$ & \multirow{3}{*}{252} & \multirow{3}{*}{0.0001} \\
\hline Themselves & $121(63.9)$ & $59(28.2)$ & $147(58.4)$ & $106(26.2)$ & & \\
\hline Price & $60(31.6)$ & $49(23.5)$ & $55(21.8)$ & $236(58.4)$ & & \\
\hline \multicolumn{7}{|c|}{ Knowledge to scientific using of dental floss } \\
\hline Yes & $89(46.8)$ & $70(33.5)$ & $132(52.4)$ & $131(32.4)$ & \multirow{3}{*}{94.4} & \multirow{3}{*}{0.0001} \\
\hline No & $49(25.8)$ & $71(33.9)$ & $76(30.1)$ & $68(16.8)$ & & \\
\hline Don't know & $52(27.4)$ & $68(32.5)$ & $44(17.5)$ & $205(50.7)$ & & \\
\hline
\end{tabular}

Table 3. Hand washing and oral hygiene practices among university students

\begin{tabular}{|c|c|c|c|c|c|c|}
\hline Characteristics & $\begin{array}{c}\text { Stage 1 } \\
\mathrm{N}=190(\%)\end{array}$ & $\begin{array}{c}\text { Stage 2 } \\
\mathrm{N}=209(\%)\end{array}$ & $\begin{array}{c}\text { Stage 3 } \\
\mathrm{N}=252(\%)\end{array}$ & $\begin{array}{c}\text { Stage 4 } \\
N=404(\%)\end{array}$ & $\mathbf{X} 2$ & $P$ value \\
\hline \multicolumn{7}{|c|}{ Washing hands before and after meals } \\
\hline Yes & $125(65.8)$ & $120(57.4)$ & $199(79)$ & $294(72.8)$ & \multirow{3}{*}{77.04} & \multirow{3}{*}{0.001} \\
\hline No & $30(15.8)$ & $20(9.6)$ & $24(9.5)$ & $5(1.2)$ & & \\
\hline Sometimes & $35(18.4)$ & $69(33)$ & $29(11.5)$ & $105(26)$ & & \\
\hline \multicolumn{7}{|c|}{ Washing hands after defecation } \\
\hline Yes & $179(94.2)$ & $190(91)$ & $238(94.4)$ & $390(96.5)$ & \multirow{3}{*}{20.86} & \multirow{3}{*}{0.001} \\
\hline No & $10(5.2)$ & $15(7.1)$ & $5(2)$ & $7(1.7)$ & & \\
\hline Sometimes & $1(1.1)$ & $4(1.9)$ & $9(3.6)$ & $7(1.7)$ & & \\
\hline \multicolumn{7}{|c|}{ Hand washing materials } \\
\hline Hand shampoo & $134(70.5)$ & $103(49.3)$ & $168(66.7)$ & $379(93.8)$ & \multirow{3}{*}{168.5} & \multirow{3}{*}{0.0001} \\
\hline Soap and water & $51(26.8)$ & $92(44)$ & $70(27.8)$ & $12(3)$ & & \\
\hline Water & $5(2.6)$ & $14(6.7)$ & $14(5.6)$ & $13(3.2)$ & & \\
\hline \multicolumn{7}{|c|}{ Duration for tooth brushing } \\
\hline Before bed & $110(57.9)$ & $78(37.3)$ & $138(54.8)$ & $254(62)$. & & \\
\hline After breakfast & $43(22.6)$ & $75(35.9)$ & $87(34.5)$ & $112(27.7)$ & \multirow{3}{*}{99} & \multirow{3}{*}{0.0001} \\
\hline After meals & $34(17.9)$ & $51(24.4)$ & $16(6.3)$ & $15(3.7)$ & & \\
\hline Sometimes & $3(1.6)$ & $5(2.4)$ & $11(4.4)$ & $23(5.7)$ & & \\
\hline \multicolumn{7}{|l|}{ Tongue Brushing } \\
\hline Yes & $49(25.8)$ & $23(11)$ & $37(14.7)$ & $49(12.1)$ & \multirow{3}{*}{109.9} & \multirow{3}{*}{0.0001} \\
\hline No & $54(28.4)$ & $79(37.8)$ & $22(8.7)$ & $56(13.7)$ & & \\
\hline Sometimes & $87(45.8)$ & $107(51.2)$ & $193(77.6)$ & $299(74.1)$ & & \\
\hline \multicolumn{7}{|c|}{ Tongue brushing material } \\
\hline Tongue brush & $3(1.6)$ & $1(0.5)$ & $17(6.7)$ & $0(0)$ & \multirow{2}{*}{40} & \multirow{2}{*}{0.0001} \\
\hline Toothbrush & $187(98.4)$ & $208(99.5)$ & $235(93.3)$ & $404(100)$ & & \\
\hline
\end{tabular}


Table 4. Objectively watched individual personal and oral hygiene among university students

\begin{tabular}{|c|c|c|c|c|c|c|}
\hline Characteristics & $\begin{array}{c}\text { Stage 1 } \\
\mathrm{N}=190(\%)\end{array}$ & $\begin{array}{c}\text { Stage } 2 \\
\mathrm{~N}=209(\%)\end{array}$ & $\begin{array}{c}\text { Stage } 3 \\
\mathbf{N}=252(\%)\end{array}$ & $\begin{array}{c}\text { Stage } 4 \\
\mathrm{~N}=404(\%)\end{array}$ & $\mathbf{X} 2$ & $P$ value \\
\hline \multicolumn{7}{|l|}{ Clean Clothes } \\
\hline Yes & $112(58.9)$ & $155(74.2)$ & $149(59.1)$ & $227(68.6)$ & \multirow{2}{*}{40} & \multirow{2}{*}{0.00001} \\
\hline No & $78(41.1)$ & $54(25.8)$ & $103(40.9)$ & $127(31.4)$ & & \\
\hline \multicolumn{7}{|l|}{ Clean hair } \\
\hline Yes & $137(72.1)$ & $150(71.8)$ & $181(71.8)$ & $291(72)$ & \multirow{2}{*}{0.009} & \multirow{2}{*}{0.9} \\
\hline No & $53(27.9)$ & $59(28.2)$ & $71(28.2)$ & $113(28)$ & & \\
\hline \multicolumn{7}{|c|}{ Fingernail trimmed } \\
\hline Yes & $26(13.7)$ & $52(24.9)$ & $67(26.6)$ & $56(13.9)$ & \multirow{2}{*}{24.5} & \multirow{2}{*}{0.00001} \\
\hline No & $164(86.3)$ & $157(75.1)$ & $185(73.4)$ & $348(86.1)$ & & \\
\hline \multicolumn{7}{|l|}{ Clean face } \\
\hline Yes & $126(66.3)$ & 144 (68.9) & $157(62.3)$ & $235(58.1)$ & \multirow{2}{*}{8.1} & \multirow{2}{*}{0.05} \\
\hline No & $64(33.7)$ & $65(31.1)$ & $95(37.7)$ & $169(41.9)$ & & \\
\hline \multicolumn{7}{|l|}{ Clean tooth } \\
\hline Yes & $145(76.3)$ & $124(59.3)$ & $137(54.3)$ & $164(39.6)$ & \multirow{2}{*}{69.8} & \multirow{2}{*}{0.00001} \\
\hline No & $45(23.7)$ & $85(40.7)$ & $115(45.7)$ & $240(59.4)$ & & \\
\hline \multicolumn{7}{|c|}{ Bad mouth breathe } \\
\hline Yes & $98(51.6)$ & $113(54.1)$ & $125(49.6)$ & $174(43.1)$ & \multirow{2}{*}{8.2} & \multirow{2}{*}{0.05} \\
\hline No & $92(48.4)$ & $96(45.9)$ & $127(50.4)$ & $230(56.9)$ & & \\
\hline
\end{tabular}

\section{CONCLUSIONS}

In conclusion, school-based hygiene education is vital in order to decrease the rates of transmissible diseases.

Our study indicates high knowledge and attitude toward personal and oral hygiene among undergraduates in comparison to earlier studies in the developing countries. Students can be educated about scientific personal and oral hygiene through sessions and training particularly in the schools, thus knowledge and attitude of the students would be improved. Accessibility of water and sanitation facilities at universities, reasons behind hand washing and brushing teeth, low cost and effective programmes are very significant to have adequate knowledge and behavior towards personal and oral hygiene and to reduce the burden of disease transmission and to stay healthy. Future research should obviously evaluate the knowledge and behaviour of the medical students towards personal and oral hygiene and obstacles of not having proper personal and oral hygiene.

\section{REFERENCES}

[1] WHO, Better health for poor children, 2009.[online]Availableat:http://www.who.int/child_ adolescent_health/documents/a91061/en/index.html [Accessed 14 ${ }^{\text {th }}$ Jan 2017].

[2] V. Curtis, L. Danquah and R. Aunger, "Planned, motivated and habitual hygiene behaviour: an eleven country review", Health Education Research, vol. 24, no. 4, pp. 655-673, 2009.

[3] WHO, Better health for poor children, 2009. [Online].Available:http://www.who.int/maternal_ch
ild_adolescent/documents/a91061/en/.[Accessed: 29-Jan-2017].

[4] R. Ejemot, J. Ehiri, M. Meremikwu and J. Critchley, "Cochrane review: Hand washing for preventing diarrhoea", Evidence-Based Child Health: A Cochrane Review Journal, vol. 4, no. 2, pp. 893939, 2009.

[5] M. Snow, G. White and H. Kim, "Inexpensive and Time-Efficient Hand Hygiene Interventions Increase Elementary School Children's Hand Hygiene Rates", Journal of School Health, vol. 78, no. 4 , pp. 230-233, 2008

[6] UNICEF. Soap, Toilets, and Taps. A Foundation for Healthy Children, 2009. [Online]. Available: https://www.unicef.org/eapro/FINAL_Showcase_do c_for_web.pdf. [Accessed: 14- Feb- 2017].

[7] Global Handwashing. October 15 is Global Handwashing Day, 2009. [Online]. Available: https://globalhandwashing.org/global-handwashingday/. [Accessed: 14- Feb- 2017].

[8] W. Oswald, G. Hunter, A. Lescano, L. Cabrera, E. Leontsini, W. Pan, V. Soldan and R. Gilman, "Direct observation of hygiene in a Peruvian shantytown: not enough handwashing and too little water", Tropical Medicine \& International Health, vol. 13, no. 11, pp. 1421-1428, 2008.

[9] R. O'Loughlin, G. Fentie, B. Flannery and P. Emerson, "Follow-up of a low cost latrine promotion programme in one district of Amhara, Ethiopia: characteristics of early adopters and nonadopters", Tropical Medicine and International Health, vol. 11, no. 9, pp. 1406-1415, 2006. 
[10] World Health Organization. World Health Statistics, 2009. [online] Available at:www.who.int/entity/whosis/whostat/2009. [Accessed 31- Mar-2017].

[11] Wanter and sanitation program. Can hygiene be cool and fun? Insights from school children in Senegal, 2009. [Online]. Available:http://documents.worldbank.org/curated/e n/765011468307739863/pdf/461950WSP0Box311f un111Senegal112007.pdf. [Accessed: 14- Jun2017].

[12] B. Scott, V. Curtis, T. Rabie and N. Garbrah-Aidoo, "Health in our hands, but not in our heads: understanding hygiene motivation in Ghana", Health Policy and Planning, vol. 22, no. 4, pp. 225233, 2007.

[13] A. Kumie and A. Ali, "An overview of environmental health status in Ethiopia with particular emphasis to its organisation, drinking water and sanitation: a literature survey", Ethiopian Journal of Health Development, vol. 19, no. 2, 2005.

[14] Rippleethiopia, Promoting Sanitation and Hygiene to Rural Households: the experience of the Southern Nations region of Ethiopia, 2008. [Online]. Available:http://www.rippleethiopia.org/documents stream/20081208-synthesissanitation-hygiene. [Accessed: 06- Jun- 2017].

[15] B. Reddy and M. Snehalatha, "Sanitation and Personal Hygiene", Indian Journal of Gender Studies, vol. 18, no. 3, pp. 381-404, 2011.

[16] R. Perry, "Francois-Joseph Belanger's Bath-House at the Hotel de Brancas", Architectural History, vol. 44, p. 377, 2001.

[17] S. Huq, S. Hossain, S. Haque and S. Akter, "Knowledge, attitude and practice on hepatitis-B infection among infected patients in a Homoeopathy Medical Center in Dhaka City, Bangladesh", South East Asia Journal of Public Health, vol. 6, no. 1, p. 27, 2016.

[18] UNICEF, school health, general and personal hygiene training manual for education supervisors and teachers in Iraq, 2006. [Online]. Available: http://washinschoolsmapping.com/wengine/wpcontent/uploads/2015/10/IraqHygiene.pdf. [Accessed: 16- Jun- 2017].

[19] Unicef, What is the Country Programme Action
Plan?,", 2011. [Online]. Available: https://www.unicef.org/uganda/CPAP_20162020.pdf. [Accessed: 14- Aug- 2017].

[20] C. Lopez-Quintero, P. Freeman and Y. Neumark, "Hand Washing Among School Children in Bogotá, Colombia", American Journal of Public Health, vol. 99, no. 1, pp. 94-101, 2009.

[21] C. Azodo, A. Ehizele, A. Umoh, P. Ojehanon, O. Akhionbare, R. Okechukwu and L. Igbinosa, "Tooth brushing, tongue cleaning and snacking behaviour of dental technology and therapist students", Libyan Journal of Medicine, vol. 5, no. 1, p. 5208, 2010.

[22] K. Peltzer and S. Pengpid, "Oral Health Behaviour and Social and Health Factors in University Students from 26 Low, Middle and High Income Countries", International Journal of Environmental Research and Public Health, vol. 11, no. 12, pp. 12247-12260, 2014.

[23] L. Singh Kaira, V. Srivastaga and D. Chopra, "Singa kaira. Oral Health Related Knowledge, Attitude And Practice Among Nursing Students Of Rohilkhand Medical College And Hospital', Indian Journal of Dental Science", Journal of Orofacial research, vol. 2, no. 1, pp. 20-23, 2012.

[24] H. Nazzal, M. Duggal, M. Kowash, J. Kang and K. Toumba, "Comparison of residual salivary fluoride retention using amine fluoride toothpastes in cariesfree and caries-prone children", European Archives of Paediatric Dentistry, vol. 17, no. 3, pp. 165-169, 2016.

[25] M. Kishi, Y. Ohara-Nemoto, M. Takahashi, K. Kishi, S. Kimura and M. Yonemitsu, "Relationship between oral status and prevalence of periodontopathic bacteria on the tongues of elderly individuals", Journal of Medical Microbiology, vol. 59, no. 11, pp. 1354-1359, 2010.

[26] T. Outhouse, R. Al-Alawi, Z. Fedorowicz and J. Keenan, "Tongue scraping for treating halitosis", Primary Dental Care, vol. 14, no. 1, pp. 11-11, 2007.

\section{ACKNOWLEDGMENT}

The authors wish to thank all students of Sulaimani polytechnic university, Sulaimani, Jihan and Komar University for allowing us to collect the data that designed the basis of this research. 